\title{
Pengaruh Myofacial Release Kombinasi dengan Hold Relax terhadap Myofacial Pain Syndrome
}

\author{
Arum Sekar Sunyiwara ${ }^{1}$, Mega Widya Putri ${ }^{2}$, Rifqi Sabita ${ }^{3}$ \\ 1. Universitas Muhammadiyah Pekajangan Pekalongan, email: sunyiwara@gmail.com
}

2. Universitas Muhammadiyah Pekajangan Pekalongan, email: megawidyaputri60@yahoo.com

3. Universitas Muhammadiyah Pekajangan Pekalongan, email: sabitarifqi18@gmail.com

\begin{abstract}
Abstrak
Pekerja garment khususnya pada bagian operator jahit merupakan salah satu pekerjaan yang beresiko terkena gangguan myofascial pain syndrome otot upper trapezius. Myofascial pain syndrome pada otot upper trapezius adalah kondisi nyeri otot leher yang ditandai adanya trigger point (titik nyeri) yang terletak di otot yang kencang, biasanya disebabkan karena beban kerja otot yang berlebihan. Sebanyak 6-67\% nyeri leher dialami oleh pekerja, 49\% diantaranya dialami pekerja garmen dan lebih banyak dialami wanita. Penelitian ini bertujuan untuk mengetahui pengaruh kombinasi myofascial release dengan hold relax terhadap myofascial pain syndrome otot upper trapezius pada pekerja garmen Kecamatan Wonopringgo. Quasi experiment dengan rancangan one group pre test-post test adalah analisa data yang digunakan, penelitian ini menggunakan sample 20 responden, dilakukan selama 2 minggu dengan tindakan yang diberikan pada penelitian ini yaitu myofascial release selama 5 menit dan hold relax selama 15 menit. Hasil dari uji paired sample t test diperoleh hasil $\rho$ value $=0,000(<0,05)$, menunjukkan bahwa ada pengaruh kombinasi myofascial release dengan hold relax terhadap myofascial pain syndrome otot upper trapezius pada pekerja garmen Kecamatan Wonopringgo.Tindakan kombinasi myofascial myofascial release dengan hold relax ini dapat digunakan untuk mengatasi myofascial pain syndrome otot upper trapezius.
\end{abstract}

Kata kunci: Myofascial Pain Syndrome, Myofascial Release dan Hold Relax.

\section{The Effects of Myofascial Release Combination with Hold Relax on Myofascial Pain Syndrome Abstract}

Garment workery especially in the sewing operators is a profession with high risk of myofascial pain syndrome disorders on upper trapezius muscle. Myofascial pain syndrome on the upper trapezius muscle is painful condition characterized by neck muscles trigger points (pain points) located on lean muscle, usually due to excessive muscle workload. As many as 6-67\% of neck pain was experienced by workers, $49 \%$ of them experienced garment workers especially female workers. This study aimed to determine the effect of the combination of myofascial release with hold relax to myofascial pain syndrome of upper trapezius muscle to garment workers in Wonopringgo District. It was a quasi experimental research with one group pre test and post test design. 20 respondent were selected through a purposive sampling technique. The treatment was given for two weeks (e.g. 3 times for each week). In each treatment,each respondent as given 5 minutes of myofascial release and 15 minutes of hold relax. The paired sample $t$ test resulted $\mathrm{p}$ value $=0,000(<0,05)$. It indicated that there wasand influence of the combination of myofascial release and hold relax to myofascial pain syndrome of upper trapezius muscle in garment workers in Wonopringgo District. Therefore the combination of myofascial release combination with hold relax can be used to treat myofascial pain syndrome of upper trapezius muscle.

Keywords : Myofascial Pain Syndrome, Myofascial Release and Hold Relax.

\section{Pendahuluan}

Nyeri leher merupakan masalah yang umum di jumpai pada masyarakat Indonesia khususnya pada pekerja yang posisi leher statis. Angka kejadian nyeri leher di Indonesia dalam 1 bulan sebesar $10 \%$, dalam 1 tahun mencapai $40 \%$.
Prevalensi nyeri leher pada pekerja mencapai kisaran 6-67\% dan lebih banyak dialami oleh wanita (Falah, 2018), dan 49\% diantaranya dialami oleh pekerja garmen (Suwantini, Wibawa, Griadhi, 2015). Posisi leher yang statis dalam jangka waktu yang lama dan beban kerja otot leher yang berlebihan dapat menyebabkan kontraksi 
otot leher yang berlebihan sehingga dapat menyebabkan nyeri, spasme pada otot leher yang disebut myofascial pain syndrome (Indriyani, 2015).

Myofascial pain syndrome adalah suatu kondisi nyeri pada otot yang bersifat kronik yang ditandai dengan adanya trigger point. Trigger point adalah titik nyeri yang hipersensitif yang terletak di otot yang menegang atau mengalami pengerasan (taut band). myofascial pain syndrome disebabkan karena beban kerja otot yang berlebihan, bisa juga disebabkan karena trauma otot. Otot yang bekerja secara berlebihan akan menyebabkan kontraksi terus menerus yang akan menyebabkan otot menjadi tegang sehingga timbul spasme, kekakuan, adhesion serta penurunan sirkulasi darah yang merupakan pemicu timbulnya trigger point di otot yang menegang (Atmadja, 2016).

Salah satu pekerjaan yang beresiko mengalami myofascial pain syndrome adalah pekerja garmen khususnya operator mesin jahit. Penjahit bekerja dengan posisi duduk tegak dan kepala agak menunduk dalam jangka waktu 7-8 jam perhari. Posisi tersebut apabila dilakukan secara berulangulang dalam jangka waktu yang lama maka akan menimbulkan berbagai masalah seperti pegal pada punggung bawah karena posisi duduk yang tidak baik, tidak sedikit juga pekerja operator mesin jahit yang mengeluhkan pegal, kaku dan nyeri pada leher karena posisi kepala yang menunduk dalam jangka waktu lama (Kinteki, 2018).

Proses menjahit merupakan proses yang menggunakan kedua tangan untuk berada diatas meja mesin jahit untuk memegang dan menjahit objek jahitan, kedua kaki menekan dinamo, dan posisi leher yang cenderung menunduk dalam jangka waktu lama (Wulandari, Moelyaningrum, Hartanti, 2017). Sebagian besar keluhan seperti nyeri leher yang dirasakan penjahit tidak tertangani oleh tim medis, karena penjahit beranggapan bahwa keluhan tersebut kerap terjadi dan akan sembuh dengan sendirinya (Buana, et al, 2017). Gangguan muskuloskeletal seperti nyeri leher apabila tidak ditangani dapat menyebabkan kekuatan otot leher menurun sehingga berdampak pada penurunan produktivitas, peningkatan resiko penyakit akibat kerja serta dapat kehilangan waktu kerja (Wahyono \& Saloko, 2014). Otot leher yang menunduk statis dan berulang-ulang dapat menyebabkan otot menegang yang akan menyebabkan nyeri, sehingga fisioterapis sangat berperan dalam penurunan nyeri leher (Falah, 2018).

Berbagai modalitas fisioterapi dapat digunakan sebagai intervensi dalam menangani nyeri sindroma miofasial otot upper trapezius antara lain spray and stretch, ultrasound (US), dry needling, ischemic compression, latihan penguluran, myofascial release, hold relax dan lain-lain (Hong, 2006). Namun peneliti memilih menggunakan metode myofascial release dan hold relax.

Myofascial release merupakan suatu teknik pemijatan yang dilakukan dengan cara menekan secara manual dengan kombinasi penguluran (stretching) pada bagian otot yang spesifik yang bertujuan untuk meregangkan ikatan jaringan yang mengalami perlengketan (Buana et al, 2017). Myofascial release merupakan salah satu terapi yang dapat diberikan untuk nyeri leher myofascial pain syndrome yang cukup efektif karena tujuan dari myofascial release adalah untuk meregangkan struktur fascia yang mengalami perlengketan atau adhesion yang menjadi penyebab timbulnya trigger point (Anggraeni,2014 dalam Alboneh, 2017).

Menurut Adler (2008), hold relax adalah salah satu teknik PNF yang bertujuan untuk meningkatkan lingkup gerak sendi (LGS) pasif dan juga untuk mengurangi nyeri. Terdapat dua macam teknik hold relax yaitu : direct treatment hold relax dan indirect treatment hold relax. Pada tesis ini penulis hanya membahas direct treatment hold relax sebagai modalitas terapi latihan. Maka pada pembahasan selanjutnya jika disebutkan hold relax pada tesis ini yang dimaksud adalah direct treatment hold relax. 
Berdasarkan latar belakang yang telah diuraikan diatas, membuat peneliti ingin mengetahui seberapa besar pengaruh pemberian intervensi myofascial release dan hold relax terhadap penurunan nyeri sindroma miofasial upper trapezius.

\section{Metode}

Desain penelitian ini adalah quasi experiment design atau sering disebut dengan rancangan penelitian eksperimen semu dengan menggunakan one group pre test and post test design.

Penelitian dilaksanakna di garmen DNY Jeans Kecamatan Wonopringgo Pekalongan, mulai tanggal 20 Mei sampai dengan 31 Mei 2019. Variabel yang akan di teliti adalah nyeri pada myofascial pain syndrome otot upper trapezius. Populasi dalam penelitian ini adalah seluruh pekerja garmen di DNY Jeans Wonopringgo Pekalongan yang berjumlah 42 pekerja

Teknik pengambilan sampel menggunakan purposive sampling dengan jumlah 20 responden yang memenuhi kriteria inklusi dan eksklusi yang telah peneliti tetapkan.

$$
\text { Aplikasi myofascial release }
$$

dilakukan untuk meregangkan struktur miofasia dan otot dengan tujuan untuk melepas perlengketan jaringan dan mengurangi nyeri. Berikan pelumas (minyak zaitun) agar pada saat memberikan myofascial release tidak mengakibatkan gesekan antara kulit pasien dan tangan terapis yang bisa menimbulkan nyeri.

Lakukan myofascial release dengan menggunakan telapak tangan dengan cara mengkombinasikan gerakan sedikit penekanan dan penguluran selama 5 menit.

$$
\text { Aplikasi hold relax dilakukan }
$$
dengan memberikan tekanan pada saat kontraksi isometrik dari otot antagonis lalu dilanjutkan dengan relaksasi. Yang dimaksud otot antagonis disini adalah otot yang menerima tahanan. Tekananyang diberikan adalah tekanansubmaksimal.

$$
\text { Pengukuran nyeri dengan }
$$
menggunakan skala VAS sebelum diberikan tindakan kombinasi myofascial release dan hold relax. Hasil dari pengukuran nyeri myofascial pain syndrome menggunakan skala VAS berupa garis lurus panjang $10 \mathrm{~cm}$ dengan keterangan: 0 (Tidak nyeri) - 10 (nyeri kemungkinan terburuk).

Data hasil pengukuran yaitu berupa angka, dengan demikian peniliti menggunakan skala pengukuran data rasio.

\section{Hasil Penelitian}

Pada bab ini peneliti membahas tentang hasil penelitian yang dilakukan pada responden garmen khususnya pada operator mesin jahit yang bekerja dengan posisi leher statis dalam jangka waktu lama. Penelitian ini dilakukan pada tanggal 20 Mei-31 Mei 2019. Jumlah sample yang digunakan pada penelitian ini sebanyak 20 responden. Karakteristik responden pada saat penelitian rata-rata umur responden adalah 26,15 dengan standar deviasi 6,699. Semua responden pada penelitian ini berjenis kelamin perempuan sesuai dengan kriteria inklusi peneliti.

Tabel 1. Distribusi frekuensi skala myofascial pain syndrome otot upper sebelum diberikan tindakan.

\begin{tabular}{llllll}
\hline Variabel & Mean & Median & SD & Min & Maks \\
\hline $\begin{array}{l}\text { Myofascial } \\
\text { pain }\end{array}$ & 3,8750 & 3,9167 & 0,69853 & 2,83 & 5,50 \\
syndrome & & & & & \\
\hline
\end{tabular}

Berdasarkan tabel 1, menunjukkan bahwa Myofascial pain syndrome pada pekerja garmen khususnya operator mesin jahit sebelum diberikan tindakan diperoleh skor minimum 2,83 dan skor maksimum 5,50 , nilai mean 3,8750 dan standar deviasi 0,6985 .

Tabel 2. Distribusi frekuensi skala myofascial pain syndrome otot upper setelah diberikan tindakan.

\begin{tabular}{llllll}
\hline Variabel & Mean & Median & SD & Min & Maks \\
\hline $\begin{array}{l}\text { Myofascial } \\
\text { pain } \\
\text { syndrome }\end{array}$ & 2,9917 & 2,9167 & 0,66331 & 2,00 & 4,67 \\
\hline
\end{tabular}

Hasil tabel 2, menunjukkan bahwa myofascial pain syndrome pada pekerja garmen khususnya operator mesin jahit 
sesudah diberikan tindakan diperoleh skor minimum 2,00 dan skor maksimum 4,67, nilai mean 2,9917 dan standar deviasi 0,66331. Nilai mean sebelum diberikan tindakan adalah 3,8750 sedangkan nilai mean sesudah diberikan tindakan adalah 2,9917 hal ini menunjukkan bahwa ada penurunan myofascial pain syndrome otot upper trapezius yang signifikan.

Tabel 3. Pengaruh Kombinasi Myofascial Release dan Hold Relax.

\begin{tabular}{lccc}
\hline Variabel & T & Df & $\rho$ value \\
\hline $\begin{array}{l}\text { MPS sebelum } \\
\text { MPS sesudah }\end{array}$ & 36,080 & 19 & 0,000 \\
\hline
\end{tabular}

Berdasarkan hasil dari tabel 3 analisa statistik menggunakan uji paired sample test didapatkan hasil $\rho$ value sebesar 0,000 dimana nilai $\rho$ value $<0,05$ maka Ho ditolak yang artinya ada pengaruh yang signifikan pada kombinasi myofascial release dengan kompres hangat terhadap myofascial pain syndrome otot upper trapezius pada pekerja garmen Kecamatan Wonopringgo.

Hasil analisa data mengenai myofascial pain syndrome pada pekerja garmen kecamatan wonopringgo sesudah diberikan tindakan kombinasi myofascial release dengan kompres hangat menunjukkan skala nyeri dengan skor minimum 2,00 dan skor maksimum 4,67, nilai mean 2,9917 dan standar deviasi 0,66331. Dari hasil yang didapatkan menunjukkan bahwa ada penurunan tingkat myofascial pain syndrome sesudah diberikan tindakan kombinasi myofascial release dengan kompres hangat.

\section{Pembahasan}

Mekanisme penurunannya adalah meningkatkan sirkulasi darah dan merileksasikan otot-otot leher sehingga nyeri berkurang (Shah \& Bhalara, 2012). Hal ini juga diperkuat oleh pernyataan dari Catau dan Gordin (2001 dalam Maruli, Sutjana, \& Indriyani, 2012) bahwa pemberian myofascial release dapat meningkatkan sirkulasi darah secara signifikan, tekanan yang dihasilkan oleh myofascial release secara cepat menimbulkan vasodilatasi sehingga terjadi peningkatan aliran darah dan volume darah yang berdampak pada penurunan nyeri.

Penelitian sebelumnya yang dilakukan oleh Werenski (2011, dalam Alboneh, 2017) menyatakan bahwa pemberian myofascial relese berpengaruh terhadap penurunan nyeri myofascial pain syndrome otot upper trapezius.

Berdasarkan hasil analisa statistik menggunakan uji paired sample $t$ test didapatkan hasil $\rho$ value sebesar 0,000 $(<0,05)$, sehingga Ho ditolak yang berarti ada pengaruh kombinasi myofascial release dengan kompres hangat terhadap myofascial pain syndrome otot upper trapezius pada pekerja garmen Kecamatan Wonopringgo.

Hasil penelitian ini sesuai dengan hasil penelitian dari Buana et all, (2017) yang menyatakan bahwa myofascial release bekerja dengan melepaskan jaringan yang mengalami perlengketan, sehingga sirkulasi darah pada area tersebut menjadi lancar sehingga akan mengurangi spasme dan nyeri. Hasil dari penelitian Werenski (2011, dalam Tryani, 2015) menyatakan bahwa pemberian tindakan myofascial release menjadi terapi yang efektif untuk kasus myofascial. Gerakan dari myofascial release sendiri merupakan gerakan pemijatan dengan cara kombinasi penekanan dan penguluran dimana cara tersebut bertujuan untuk mengulur atau meregangkan struktur fascia dengan tujuan untuk melepas perlengketan yang akan mengurangi nyeri serta memulihkan kualitas cairan pelumas dari jaringan fascia.

Hasil penelitian ini juga sesuai dengan penjelasan dari Boonruab et al (2018) yang menjelaskan bahwa kompres hangat memberikan rasa nyaman yang akan berdampak pada penurunan nyeri, penurunan spasme otot dan memberikan efek hangat pada area tersebut, kompres hangat memiliki dampak fisiologis bagi tubuh, dimana akan menyebabkan 
vasodilatasi pembuluh darah yang akan mengakibatkan sirkulasi darah dan asupan oksigen menjadi lancar sehingga akan mengurangi rasa nyeri.

Intervensi hold relax dapat mempengaruhi proses metabolik. Hasil sisasisa metabolisme tubuh dengan terjadinya peningkatan volume darah dan aliran darah pada area tersebut dapat menyebabkan area tersebut membuang sisa-sisa metabolisme atau cairan yang berlebihan, sehingga terjadi penurunan nyeri yang berakibat menurunnya disabilitas leher. Latihan isometrik dengan tekanansub maksimal membanttu pasien untuk menyadari penggunaan otot secara benar. Latihan isometrik dengan beban maksimal 1-2 Lb serta repetisi yang lebih akan meningkatkan kekuatan otot funsional dan endurance (kisner, 2012) Efek ini akan memberikan koreksi terhadap postur dan secara bertahap keluhan berkurang dan disabilitas leher akan menurun.

\section{Simpulan}

Ada pengaruh yang signifikan kombinasi myofascial release dengan hold relax terhadap myofascial pain syndrome otot upper trapezius pada pekerja garmen Kecamatan Wonopringgo berdasarkan hasil analisa statistik menggunakan uji Paired sample $\mathrm{t}$ test didapatkan hasil $\rho$ value sebesar $0,000(<0,05)$.

Penelitian ini diharapkan dapat menjadi pertimbangan bagi peneliti lain untuk melakukan penelitian dengan intervensi lain pada myofascial pain syndrome otot upper trapezius khususnya dalam mengurangi nyeri.

Penelitian ini diharapkan dapat ditindak lanjuti untuk melakukan pengabdian masyarakat program studi sarjana fisioterapi dalam memberikan intervensi yang komprehensif khususnya muskuloskeletal untuk menurunkan nyeri myofascial pain syndrome otot upper trapezius. Bagi peneliti selanjutnya perlu menggali faktor-faktor lain yang dapat mempengaruhi.

\section{Ucapan Terimakasih}

Peneliti mengucapkan terimakasih pada

Kemenristekdikti, Rektor Universitas

Muhammadiyah Pekajangan Pekalongan (UMPP), Lembaga penelitian dan Pengabdian Masyarakat (LPPM) Universitas Muhammadiyah Pekajangan Pekalongan, Kepala Badan Penelitian Daerah (BAPEDA), pemilik garmen DNY jeans dan seluruh responden yang telah mendukung pelaksanaan penelitian

\section{Daftar Pustaka}

Atmadja, S.A. (2016). Sindrome Nyeri Myofascial. Continuing Medical Education, vol. 43 no. 3, hh. 176-177.

Boonruab, J, Damjuti,W, Niempoog, S \& Pattaraarchachai, J. (2018). Effectiveness of Hot Herbal Compress Versus Topical Diclofenac in Treating Patients With Myofascial Pain Syndrome. Journal of Traditional and Complementary Medicine, Thailand.

Buana, T.M.N, Purnawati, S, Sugijanto, Satriyasa, K, Sandi, N \& Imron, A.M. (2017). Perbedaan Kombinasi Myofascial Release Technique dengan Ultrasound dan Kombinasi Ischemic Compression Technique dengan Ultrasound dalam Meningkatkan Kekuatan Otot Leher Akibat Sindroma Myofascial pada Penjahit Pakaian di Kabupaten Gianyar. Sport and Fitness Journal, vol. 5, no. 3, hh. 71-77.

Falah, M.A. (2018). Pengaruh Penambahan Stretching Exercise pada Kompres Panas terhadap Penurunan Nyeri pada Neck Pain Syndrome. Jurnal Skripsi Fisioterapi. Universitas Muhammadiyah Surakarta.

Indriyani, N.K. (2015). Pengaruh Myofascial Release terhadap Pengurangan Nyeri pada Myofascial Trigger Points Syndrome Otot Upper Trapezius pada Pembatik di Desa Jarum Bayat. Jurnal Skripsi Fisioterapi. Universitas Muhammadiyah Surakarta.

Kinteki, L.Z. (2018). Pengaruh Kinesio Taping dan Muscle Energy Technique 
terhadap Penurunan Nyeri Myofascial Pain Syndrome Otot Upper Trapezius pada Penjahit di Adevia Konveksi. Jurnal Skripsi Fisioterapi. Universitas Muhammadiyah Surakarta.

Kisner, C \& Colby, A.L. (2014). Terapi Latihan Dasar dan Teknik. Jakarta, EGC.

Kisner, C \& Colby, A.L. (2017). Intisari Terapi Latihan Buku Praktik Klinik. Jakarta, EGC.

Shah, S \& Bhalara, A. (2012). Myofascial Release, International journal of Health Science and Research, vol. 2.

Suwantini, P.W.N, Wibawa, A \& Griadhi, A.P.I. (2015). Auto Stretching Lebih Menurunkan Intensitas Nyeri Otot Upper Trapezius Daripada Neck Cailliet Exercise pada Penjahit Payung Bali di Desa Mengwi Kecamatan Mengwi Kabupaten Badung. Jurnal Skripsi Fisioterapi. Universitas Udayana.

Wahyono, Y \& Saloko, E. (2014). Pengaruh Workplace Exercise terhadap Keluhan Muskuloskeletal pada Pekerja di Bagian Sewing CV. Cahyo Nugroho Jati (CNJ) Sukoharjo. Jurnal okupasi Terapi. Kementerian Kesehatan Politeknik Kesehatan Surakarta.

Waslaski, J. (2012). Clinical Massage Therapy A Structural Approach to Pain Management.

Wulandari, R.D, Moelyaningrum, D.A \& Hartanti, I.R. (2017). Risiko ergonomi dan Keluhan muskuloskeletal Disorders pada Pekerja Jahit (Studi Di UD. Ilfa Jaya Konveksi Banyuwangi-Indonesia). Prosiding Seminar Nasional, Universitas Airlangga. 